\title{
The Strategies for Strengthening National Geographic Information Infrastructure in Nepal
}

\author{
Nab Raj Subedi \\ Chief Survey Officer, Land Management Training Centre (LMTC), \\ Ministry of Land Reform and Management, Nepal \\ nawraj_s@yahoo.com,subdi03939@itc.nl
}

\section{Keywords:}

partnership

NGII, SDI Policy, strategies, standards,

\section{Abstract}

Nepal has already initiated the National Geographic Information Infrastructure activities (NGII). For a successful implementation of a National Geospatial Data Infrastructure (NGDI), there is a need for a national policy that will provide the necessary guidelines, identify various committees to be responsible for the various aspects of the NGDI (such as standards, custodianship, sharing and partnership) and provide issues that are acting as the constraints against the take off of the NGDI. The issues must be discussed at a forum where all the stakeholders would meet to discuss on the various issues in the draft policy prior to the approval. There is also a need for an agency to be the lead agency in the development of a NGDI, for which the prevalent NGIIP can be given authority to act as a coordinator until the formation of the National Geographic Information Council. This paper highlights that each stakeholder organization must have certain strategies that work in resonance with broad SDI strategies that perform NGII development and proposes its mission, vision and some general policy statements for the development of SDI activities in Nepal. Some goals and corresponding strategies identified as an outcome of recently held evaluation research on NGII has been provided as an aid for its development.

\section{Introduction}

Geographic Information System (GIS) activities were initiated in Nepal during the National Eighth Plan period between 1992-1997 (Chhatkuli 2002). The emergence of IT Policy in 2000 led the growth of GIS activities in the country (NPC 2001). The National
Eighth Plan (1992-1997) period witnessed many sporadic creations of spatial databases and mushrooming of isolated GI systems, most of which started from independent digitization of the then existing out-of-date topographic maps therefore duplicating much of the efforts. The Ninth Plan (1997-2002) focused on the use of geographic information and spatial data by mentioning importance of GIS in many occasions (Chhatkuli and Kayastha 2005). The base paper of the Tenth Plan (2002-2007) mentioned the importance of a geographic information infrastructure and national geographic information system for an easy access and dissemination of geographic information (NPC 2002). Consequently, in the year 2002, the then Government of Nepal initiated a National Geographic Information Infrastructure Programme (NGIIP) with one of the pronounced objectives of avoiding duplication in spatial data creation and usage through the networking of different GI Systems in the country. In this way, NGIIP initiative formed a national level SDI in the country (Chhatkuli and Kayastha 2005).

National Geographic Information Infrastructure programme (NGIIP) has been launched by the initiation of the Survey Department, the National Mapping Organisation (NMO). It started functioning by launching metadata of framework data (Chhatkuli 2003). There are different stakeholders from the central government agencies as well as some district level offices situated at different parts of the country in the NGIIP network. Records from NGIIP show that hundreds of users have acquired spatial information from NGII platform so far. To see whether NGII has fulfilled user expectations, evaluation was necessary.

Therefore, a research was carried out to see the success of NGII in terms of user satisfaction perspective. An index was derived by integrating all of the measured satisfaction on weight assigned indicators to denote the level of success. It was found that the success level of NGII is below the "slightly satisfied level i.e. 1" although positive with an overall mean success index of $18 \%$ in 
comparison to the extremely satisfied conditions in an ideal case $(100 \%)$. The research indicated that the low level of satisfaction on NGII mostly accounts to the factor "effort applied for national policies and technical standard" on which the level of satisfaction was 0.01 (almost zero in the measurement scale) which indicates that there is no such policy existing in the country that stimulates and support NGII. Similarly, indicators like availability, accessibility, means of request and completeness are in a very low level of positive satisfaction. The reliability of the system and completeness of information also show the very low level of satisfaction, in spite of their recognizance as important factors.

\section{A time to reverse the approach for NGII}

Nepalese NGII developers have done quite a lot (particularly spatial base-data generation) following the bottom up approach such as generation of national multiresolution topographic database, metadata publication of basic topographic database and clearinghouse setup. But it lacks important aspects such as institutional and legal framework. It lacks coordination mechanism and there is no spatial information policy. These issues need to be solved through the higher level bodies of government. Data itself is not everything for SDI realisation. Therefore, it is seen that the bottom up approach of SDI realisation has a certain degree of saturation (after the data or certain technology set up), after which the process must be reversed such as top-down approach for actual realisation. $40 \%$ of respondents from the policy level explicitly remarked that "the adoption of bottom up approach" itself is responsible for the current plight of Nepalese NGII whereas some of the respondent themselves acknowledged that the time to reverse the approach has arrived. This indicates that NGII can not be fully realised only from the bottom up approach. Of course, it is useful for initializing NGII activities such as data generation in the stakeholder organisations. On the other hand, it equally needs top-down exercise such as generation of broader policy framework and bringing broader (not only confined to single organisation) strategies for NGII realisation. Bottom-up approach provides experience to the players and designers based on which spatial information policies is formulated and legal and organisational framework are set up. The proposed strategies, that support for NGII development assumes that present NGIIP under the Survey Department (NMO) should take initiative role for this in such a way that its business strategy must be aligned with that of other stakeholder organisations and the ICT strategies must be aligned with ICT strategies of each organization similar to what Henderson and Venkatraman (1999) contend on their strategic alignment models.
"Innovation like a SDI is not an entity that comes out of spontaneous creation by somebody", as stated by NRC (1993), "It is an ad hoc affair". The only important aspect is to put its component (such as data, metadata etc) in a coordinated and well arranged order on the backdrop of policy, standard, cooperation and coordination. The strategies formulated as a result of this study are for the improvement of NGII but not focused on a particular stakeholder organisation that has a stake in it. Therefore, these strategies are referred as broad strategies. It is believed that until there is a national focus, an NGII cannot be developed. This necessitates: communication between the potential partners, identification of priorities areas of different sectors and their link with NGII; development of implementation plan with consensus of stakeholders; and mutual exchange and enhancement of knowledge. Similarly, strategic organizational framework is of vital importance for NGII development. For this, development of categorical strategies and adoption of strategic alignment by each of the stakeholder organisations and strengthening of relation with similar international organizations is essential. Culture of use of spatial data in decision making process helps to promote NGII development. This can be enhanced by creating metadata and prototyping of application that can be used in the decision making process. These developments can only be realized if there is a proper guideline in terms of strategies. This is only possible if players at higher level play an active and creative role to realize NGII.

\section{Institutional situation of NGIIP}

This section searches for any existing arrangements that are key to: easy access to the national data asset components owned by different stakeholders; ensuring the maintenance of these data and its related metadata; avoidance of duplication of efforts and resources invested in data collection; development of standard in compliance to the national or international standards and identifying and developing core datasets.

\subsection{The Policy Problems}

Although the national periodic plan documents spell out gradual evolution of surveying and mapping and geo-spatial data activities in Nepal (Chhatkuli 2007), NGII in Nepal still suffers from the lack of formal policy framework to facilitate the development of SDI. Organizations do not have clear mandate for data dissemination in the policy context. Present distribution of geo-information from NGIIP as the products of Survey Department is only an extension of distribution of hardcopy information based on Article 2 ka 1 of Land (Survey and 
Measurement) Act, 1963 of Nepal. As a result, unauthorised agencies may involve selling the data derived by the other organisations. The copyright legislation has not been effective for spatial data distribution and use, resulting to ad-hoc arrangement for data distribution, which is not beneficial for the government and private sector. It simply indicates that there is a lack of custodianship.

Lack of policies for institutionalisation of NGIIP and its activities, pricing and standard of spatial data, use of technology and human resource development, coordination, cooperation and use of spatial data have hindered the development of NGII, the reason for which a number of stakeholders have remain fixed in the NGII platform since the beginning of the programme. Figure 1 indicates different policy problems existing in Nepal hindering the development of a coherent NGII, as responded by different stakeholders.

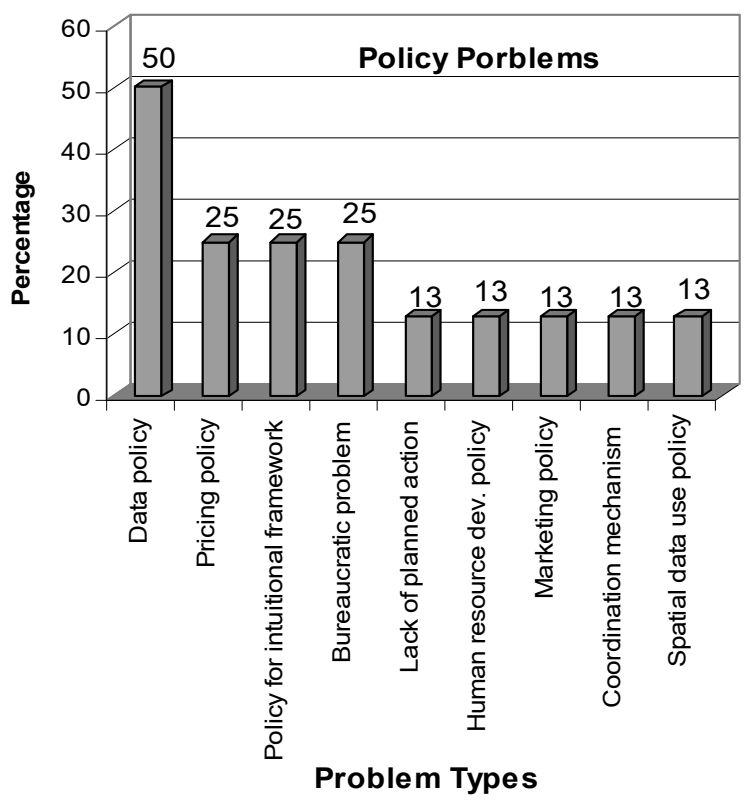

Figure 1: Indicating the existence of policy problem in NGII environment

\subsection{Standards}

Standard development and implementation for spatial data was found to be existing but for only NTDB with some limitation with respect to its content. Since duplicated data (digitized separately) has been found being provided by different agencies on their own, there are not at standards. At the same time, all the sampled user organizations are using these differently sourced data. Consequently, users are facing problem while they overlay these data acquired from different sources such as ICIMOD, NGII, KMC or DUDBC as they apply different coordinate and projection system for the data.
The existing data cannot be easily integrated (no common reference system) due to variations in projections and other data quality aspects. There are no national standards adopted on data formats and content in spite of the publication of standard for NTDB by SD. On the other hand, the standards published falls short in the context of the measure of availability of information at present (such as information from the satellite images). Most institutions develop or adopt their own local standard therefore rendering difficulties in data sharing.

This has caused serious problems for users while they run overlay operations in GIS hence causes un-satisfaction. However, in spite of the existence of differences in standard, majority of the user responded that data from NGIIP are mostly used because it is produced by NMO which have published standard and bears metadata in the clearinghouse. Standard published by SD has provided at least some degree of satisfaction in comparison to that data provided by the other organisation.

It is observed that data produced in NGIIP has been seen to be produced using the same software as being used by most of the sampled user. This has set an ad hoc standard of spatial data (vendor based format), at least solving immediate problems. Users' responses on standard among data producers shows that the available standard is not sufficient since it does not explains the data reliability, completeness, accuracy etc.

\subsection{Organizational structure of NGIIP}

The organisational stature of NGIIP can be viewed from different perspective: number of partners in NGIIP development; position of NGIIP in Nepalese administrative structure; realisation of proposed National Geographic Information Centre (NGIC); human resources; coordinating role in NGII environment.

NGIIP exists as a physical organisation for SDI activities, with the leadership of Survey Department. The organisations involved in the NGII in the initial stages were SD, CBS, MLD, MOPE, MOAC and DHO (Lahmeyer International 2005) as well as 33 Branch Statistics Offices (BSOs) scattered in the different parts of the country. Out of the main six stakeholders, MOPE does not exist as a stakeholder any more since it was disintegrated and merged with the other Ministry (Interview, Kaystha, 2008). This makes the number of stakeholders to be reduced to 5 , excluding BSO offices.

Emergence of IT policy, copyright laws indicate that Nepal is practicing to enter into the IT based governance (NPC 2001). However, It has not been able to come out of the bureaucratic system (Sapkota 1997; Shukla 2005). 
This is also reflected in NGII. Analysis revealed that the placement of NGIIP under the Survey Department has been controversial. Administrative position of NGIIP in the vertical structure of Nepalese Bureaucracy shows that it is below the department level, whereas its connection is with the organization from the Ministry level to the District level as shown in figure 2. their representatives (NGIIP 2008) including personnel from NGIIP. However, these committees have not been able to formulate a single draft policy so far.

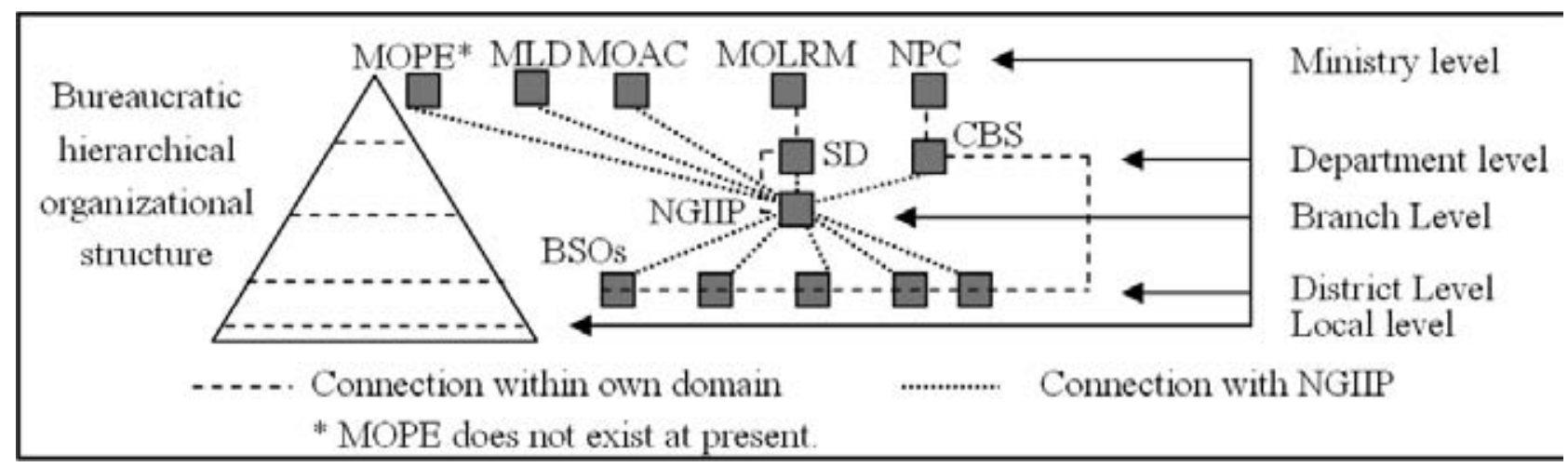

Figure 2: Position of NGIIP in the bureaucratic hierarchal organizational structure in Nepal

A close look on the notion of the respondents revealed that the given position of NGIIP below the Ministry level has deprived it to play the role as a coordinator in NGII since the bureaucratic circular prevents it to have an easy access to and communication with Department-Ministry or Ministry-NGIIP. Bearing in mind that such scenario would develop whereby NGIIP might not be able to perform the way it is expected due to its placement in a position not comfortable to the other ministry level organizations, the concept of formation of the National Geographic Information Centre (NGIC) had been proposed by NGIIP at the beginning of NGII process in Nepal Which, unfortunately, has not been able to be recognized due to varieties of reasons.

\section{Human resources at present in NGIIP}

Information gathered showed that NGIIP has a number of experts in the geo-information field but it does not have a single expert in domain of ICT which has posed difficulties in development of mechanism for dissemination of existing information available in NGIIP. For ICT purpose, NGIIP is opting for outsourcing mechanism only as a short term solution whereas, for a long term solution, it needs its own IT people, which is lacking completely.

\section{Formation of different committees}

Different working groups have been observed to be formed to assist the Programme Management Unit (PMU) of NGIIP. Working Groups, where all the stakeholders have

\section{Towards the formulation of strategies for developing NGII}

After the evaluation of NGII and validation of the calculated success measurement (not part of this paper), strategies for NGIIP were formulated. Firstly, eyes were given for any existing goals and strategies of NGIIP and subsequently internal and external scanning of NGII was carried out and finally strategies were formulated.

\subsection{Present goals of NGIIP}

Currently no goal and strategies have been found formulated for the development of NGIIP. However documents related to NGIIP indicates that it has been initiated with an overall objective and purposes viz. (i) With the overall objectives of developing a National Geographic Information Infrastructure in the country to strengthen the planning and resource management, NGII program was initiated (Budhathoki and Chhatkuli 2004). (ii) The specific purposes of establishment were to develop an NGII platform to facilitate data sharing among the Central Bureau of Statistics, Survey Department and participating agencies, and disseminate Population and Hosing Census 2001 results via the NGII platform(Kayastha and Chhatkuli 2005).

Currently, it is found to be working based on approved annual programme (as unanimously indicated respondent stakeholder). A budget distribution sheet has been the blue print document of actions for a given year to NGIIP. Document bearing the action plan or specifies 
business and ICT strategies has not been defined due to lack of active partnership for NGII development. It was observed that Lack of proper business process in the absence of strategic alignment for data sharing and establishment of good partnership mechanism has posed a threat of disintegration of stakeholders from NGIIP platform. Cases have been identified where the current stakeholders are endeavouring in an isolated fashion to establish an information system where NGIIP remains completely unknown.

\subsection{Formulation of strategies}

An SDI activity takes place in multi-stakeholder environment for which primary requisites are coordination, cooperation and partnership apart from data being possessed by these stakeholders. We ( the author and his research supervisors) therefore contend that a hierarchal framework of strategies is required having: (i) a set of broad strategies that provides a guideline for creating an environment of coordination, cooperation and partnership among stakeholders for spatial data sharing, (ii) strategies for individual organisation required for strategic alignment for an improved business process and to achieve customer satisfaction as well as to cope with changes brought about by external and internal situation. Although there are overlaps in these two ways of viewing strategies, here we select to discuss the first since the second one differs from organisation to organisation and falls outside the scope of study. In the situation that NGIIP is already present in Nepal, and also based on the information that we derived from interviews with stakeholders, NGIIP is supposed to carry out the action plan and work towards the implementation of such strategies for improving SDI activities in the country support other stakeholder organisations towards strategic alignment. It is because a coherent SDI cannot be realized if individual organisations are weak in performance due to lack of their business and ICT strategies.

\subsubsection{SWOT analysis}

We now carryout SWOT analysis based on the information we discussed in the previous sections. We analyze the above mentioned strengths, weaknesses, opportunities and threats by putting them in the matrix of SWOT. However, we only provide the formulated strategies in the matrix of SWOT due to limitation of space.

\begin{tabular}{|c|c|c|}
\hline & Strength & Threats \\
\hline$F$ & $\begin{array}{l}\text { ST-Strategies } \\
\text { - Use the EU funded resources for other } \\
\text { stakeholder organization for cost recovery } \\
\text { - Adopt market orientation for making } \\
\text { product more sellable by analyzing the user } \\
\text { requirements } \\
\text { - Diversify the product } \\
\text { - Adopt user-convinced pricing mechanism so } \\
\text { that it provides some degree of security to the } \\
\text { data. } \\
\text { - Expand consciousness against piracy } \\
\text { and duplication through the website of } \\
\text { stakeholders } \\
\text { - Use standards and copyright and develop total } \\
\text { quality management to secure data } \\
\text { - Increase communication between stakeholders } \\
\text { so that they would turn towards a singular } \\
\text { NSDI or to align NGII initiatives for all sectoral } \\
\text { priorities } \\
\text { - Invest for refresher course to enhance the skill } \\
\text { of the staffs on new technology. } \\
\text { - Generate prototype to convince the policy } \\
\text { makers so that they would bring required } \\
\text { policy as soon as possible }\end{array}$ & $\begin{array}{l}\text { WT-Strategies } \\
\text { - Adopt customer or user orientation for enhancing } \\
\text { customer satisfaction so that rate of transaction increase } \\
\text { to meet the financial needs. } \\
\text { - Develop categorical strategies (long term and short } \\
\text { term) based on the experience of business process and } \\
\text { information at hand to avoid the effect of instability of } \\
\text { government } \\
\text { - Convince stakeholders through regular interaction so } \\
\text { that they are inclined singular spatial data infrastructure } \\
\text { in the country in the national level. } \\
\text { - Use EU funded resources for cost recovery of the } \\
\text { stakeholder organization. } \\
\text { - Simplify the work process for increasing timeliness } \\
\text { and responsiveness. }\end{array}$ \\
\hline
\end{tabular}

Continued SWOT matrix... 


\begin{tabular}{|c|c|c|}
\hline & Strengths & We a knesses \\
\hline 0 & $\begin{array}{l}\text { SO-Strategies } \\
\text { - Take a coordinating role by establishing } \\
\text { relationship with stakeholders } \\
\text { - Define fundamental datasets that can be } \\
\text { placed in the national directories and Identify } \\
\text { the custodian of these datasets } \\
\text { - Support and encourage to train the staffs } \\
\text { of other stakeholder organization in geo- } \\
\text { informatics. } \\
\text { - Provide financial and/or and technical } \\
\text { support to the other stakeholder organization } \\
\text { to generate the prioritized spatial dataset } \\
\text { - Support to publish metadata of the spatial } \\
\text { dataset lying in the stakeholders organization } \\
\text { through the availed clearinghouse } \\
\text { - Enhance user consciousness by interacting } \\
\text { with user forum and stakeholders and increase } \\
\text { the number of stakeholders in the network of } \\
\text { NGIIP } \\
\text { - Provide a framework for policies for } \\
\text { development of spatial data policies, standard } \\
\text { that enhances accessibility } \\
\text { - Formulate polices for standards, data sharing } \\
\text { and distribution with the intensive interaction } \\
\text { with stakeholders } \\
\text { - Develop implementation plan for NGII with } \\
\text { the consent and support of stakeholders. } \\
\text { - Develop online fundamental data serving } \\
\text { system through NGIIP } \\
\text { - Strengthen relationship with International } \\
\text { SDI organizations such as ISDI, GSDIA and } \\
\text { PCGIAP and extend with other to learn and } \\
\text { observe the strategic framework they have } \\
\text { developed }\end{array}$ & $\begin{array}{l}\text { WO-Strategies } \\
\text { - Employ ICT staff in stakeholders organization by } \\
\text { convincing the policy makers to accelerate the } \\
\text { dissemination process in the event of existing human } \\
\text { resource policy } \\
\text { - } \text { Adopt strategic alignment in stakeholder organizations } \\
\text { by making fit of their Business and ICT strategy with } \\
\text { organizational and ICT infrastructure by utilizing } \\
\text { the existing (and modifying) business process and } \\
\text { technology through user requirement study. } \\
\text { - Employ a convincing pricing model based on } \\
\text { interaction with users and convince the policy maker } \\
\text { for bringing a pricing policy that allows adopting } \\
\text { flexibility in price fixation. } \\
\text { - Identify the priorities of different sectors and their } \\
\text { link with NGII } \\
\text { - Convince and support policy makers to develop } \\
\text { understanding and bring such a spatial policy that } \\
\text { streamlines all stakeholders to be cooperative for data } \\
\text { sharing and enhance use of spatial data and publish } \\
\text { their metadata } \\
\text { - Adopt customer orientation by utilizing existing } \\
\text { technology and freeware to develop automated } \\
\text { system of product and service delivery and entertain } \\
\text { the digital request for data and service. } \\
\text { - Transfer knowledge to create and update spatial } \\
\text { information by making use of the latest technology } \\
\text { and skilled manpower. } \\
\text { - Provide incentives to the involved staff by sending } \\
\text { them in the refresher course and establishing an award } \\
\text { system to the well performer. } \\
\text { - Transform NGIIP into NGIC ( with a status of } \\
\text { ministerial or high commission level) }\end{array}$ \\
\hline
\end{tabular}

\subsection{Goals and associated strategies for Improvement of NGII}

Four goals are proposed for developing NGII in Nepal. Corresponding performance measure and associated strategies has been specified below.

\subsubsection{Goal 1: Succeed in getting a National focus for Developing National Geographic Information Infrastructure}

\section{Performance measure 1:}

Half yearly seminars (for 2 years) with participation of all central level government agencies, major private user organizations and publication of the outcomes 


\section{Strategies:}

1.1 Increase communication between stakeholders so that they would turn towards a singular NSDI or to align NGII initiatives for all sectoral priorities

1.2 Convince and support policy makers to develop understanding and bring such a spatial policy that streamlines all stakeholders to be cooperative for data sharing and enhance use of spatial data and publish their metadata

1.3 Enhance user consciousness by interacting with user forum and stakeholders and increase the number of stakeholders in the network of NGIIP.

\subsubsection{Goal 2: Realize strategic organizational framework for National Geographic Information Infrastructure}

\section{Performance measure 2:}

Measure customer satisfaction with the criteria that $80 \%$ of the sampled stakeholders (stratified sample) must have quite satisfied situation on the selected indicators

\section{Strategies:}

2.1 Develop categorical strategies (long term and short term) based on the experience of business process and information at hand to avoid the effect of instability of government

2.2 Adopt strategic alignment in stakeholder organizations by making fit of their Business and ICT strategy with organizational and ICT infrastructure by utilizing the existing (and modifying) business processes and technology through user requirement study.

2.3 Strengthen relationship with International SDI organizations such as ISDI, GSDIA and PCGIAP and extend with others to learn and observe the strategic framework they have developed.

\subsubsection{Goal 3: Improve existing National Geographic Information Infrastructure in Nepal}

\section{Performance measure 3:}

$80 \%$ of participating stakeholders must have their sectoral priorities, working plan and sharable data (for 37 districts) within 2 years of the work

\section{Strategies:}

3.1 Identify priorities of different sectors and their link with NGII.

3.2 Develop implementation plan for NGII with the consent and support of stakeholders.

3.3 Transfer knowledge to create and update spatial information by making use of the latest technology and skilled manpower.

\subsubsection{Goal 4: Improve culture of use of geo- information for planning and informed decision making}

\section{Performance measure 4:}

Publication of metadata by $80 \%$ of the stakeholders in the platform of NGIIP.

\section{Strategies:}

4.1 Provide a framework for policies for development of spatial data policies, standard that enhances accessibility

4.2 Support and encourage training the staffs of other stakeholder organization in geo-informatics.

4.3 Support to publish metadata of the spatial dataset lying in the stakeholders organization through the available clearinghouse

4.4 Generate prototype to convince the policymakers so that they would bring required policy as soon as possible.

\section{Conclusion}

The discussion in this paper can be concluded as follows:

(i) Effective national policies, strategies, and organizational structures need to be established at the national level for the integration or national spatial data collection, use, and distribution and sharing.

(ii) The National Geographic Information infrastructure programme is required to continue to be the working body for NGII activities until the formation of National geographic Information Council that shall coordinate the interagency program in future. The responsibilities of NGIIP should be redefined based on the consensus of stakeholder and user organizations. 
(iii) We need to expand the development and speed the creation and Implementation of standards (content, quality, performance, and Exchange), procedures, and specifications for spatially referenced digital data, and create a series of incentives, particularly among national agencies, that would maximize the sharing of spatial data and minimize the redundancy of spatial data collection.

(iv) Procedures should be established to foster ready access to information describing spatial data available within government and the private sector through existing networks, thereby providing online access by the public in the form of directories and catalogs.

\section{References}

1. Budhathoki, N. R. and Chhatkuli, R. R. (2004). Building Geographic Information Infrastructure at National Level: Nepalese Experience. Global Spatial Data Infrastructure, 7th Conference, Banglore, India, GSDI.

2. Chhatkuli, R. (2002). "National Geographic Information Infrastructure Programme to Support National Geographic Information System in Nepal." Nepalese Journal on Geoinformatics 1: 49.

3. Chhatkuli, R. (2003). "Data dissemination, copyrights and pricing and institutional issues in the context of a national geographic information infrastructure and the role of Survey Department in Nepal." Workshop on "Role of Survey Department in the Context of NGII in Nepal". 9.

4. Chhatkuli, R. R. (2007). "From Cadastral Plan to Geographic Information Infrastructure: Fifty Years of Evolution Of Geo-Spatial Data Policy In Nepal." Nepalese Journal on Geoinformatics 6(1): 125.

5. Chhatkuli, R. R. and Kayastha, D. M. (2005). Towards a National Geographic Information Infrastructure: Overcoming Impediments to the Development of SDI in Nepal. From Pharaohs to Geoinformatics, Cairo, Egypt, FIG.

6. Government of Nepal (2000). "Information Technology Policy."

7. Government of Nepal (2007). "Interim Constitution of Nepal."

8. Henderson, J. C. and Venkatraman, N. (1999). "Strategic alignment: Leveraging information technology for transforming organisation." IBM Systems 38(2\&3): 472-484.
9. Kayastha, D. M. and Chhatkuli, R. R. (2005). Survey Department and the Context of Geographical Information Infrastructures. Colloquium on the role and functions of Survey Department in the Context of Broader Technological Development, Kathmandu, Nepal, Survey Department

10. Lahmeyer International (2005). Final Report. Kathmandu, Population and Housing Census 2001: Mapping Component: 218.

11. NGIIP. (2008). "National geographic Information Infrastructure Program." Retrieved 11 December, 2008, from http://www.ngiip.gov.np/index.php.

12. NPC(2001).Information Technologyfor DevelopmentIT Policy and Strategy Papers for Nepal. N. National Planning Commission. Kathmandu, Nepal.

13. NPC (2002) The tenth five-year plan of His Majesty's Government of Nepal. Volume, DOI:

14. NRC. (1993). "Toward a Coordinated Spatial Data Infrastructure for the Nation." from http://www.nap. edu/catalog.php?record_id $=2105$.

15. NRC. (1994). "Promoting the National Spatial Data InfrastructureThrough Partnerships." from http:// www.nap.edu/catalog.php?record_id $=4895$.

16. Sapkota, B. N. (1997). "Building Partnership Reforms in the Nepalese Bureaucracy." Asian Review of Public Administration VIX(1).

17. Shukla, D. (2005). Modernizing Bureaucracy through E-Governance in Nepal Global Blues and Sustainable Development: The Emerging Challenges for Bureaucracy, Technology and Governance, University of South Florida, International Political Science Association (IPSA) Research Committee 4.

18. Todorovski, D. and Lemmen, C. (2007). Analyses of User Requirements - The First Step towards Strategic Integration of Surveying and Cadastral Services. XXX FIG Working Week and General Assembly : Strategic Integration of Surveying Services, Hong Kong SAR, China, FIG. 